\title{
A DeoR-Type Transcription Regulator Is Required for Sugar-Induced Expression of Type III Secretion-Encoding Genes in Pseudomonas syringae pv. tomato DC3000
}

\author{
Sydney E. Turner, ${ }^{1,2}$ Yin-Yuin Pang, ${ }^{1}$ Megan R. O'Malley, ${ }^{1}$ Alexandra J. Weisberg, ${ }^{1}$ Valerie N. Fraser,,${ }^{1,3}$ \\ Qing Yan, ${ }^{1}$ Jeff H. Chang, ${ }^{1,4}$ and Jeffrey C. Anderson ${ }^{1,+}$ \\ ${ }^{1}$ Department of Botany and Plant Pathology, Oregon State University, Corvallis, OR 97331, U.S.A. \\ ${ }^{2}$ Honors College, Oregon State University \\ ${ }^{3}$ Molecular and Cellular Biology Program, Oregon State University \\ ${ }^{4}$ Center for Genome Research and Biocomputing, Oregon State University
}

Accepted 10 December 2019.

\begin{abstract}
The type III secretion system (T3SS) of plant-pathogenic Pseudomonas syringae is essential for virulence. Genes encoding the T3SS are not constitutively expressed and must be induced upon infection. Plant-derived metabolites, including sugars such as fructose and sucrose, are inducers of T3SSencoding genes, yet the molecular mechanisms underlying perception of these host signals by $P$. syringae are unknown. Here, we report that sugar-induced expression of type III secretion $A$ (setA), predicted to encode a DeoR-type transcription factor, is required for maximal sugar-induced expression of T3SS-associated genes in $P$. syringae DC3000. From a Tn5 transposon mutagenesis screen, we identified two independent mutants with insertions in setA. When both setA::Tn5 mutants were cultured in minimal medium containing fructose, genes encoding the T3SS master regulator $\operatorname{HrpL}$ and effector AvrRpm1 were expressed at lower levels relative to that of a wild-type strain. Decreased $h r p L$ and avrRpml expression also occurred in a setA::Tn5 mutant in response to glucose, sucrose, galactose, and mannitol, demonstrating that setA is genetically required for T3SS induction by many different sugars. Expression of upstream regulators $h r p R / S$ and $r p o N$ was not altered in setA::Tn5, indicating that SetA positively regulates $h r p L$
\end{abstract}

\section{S. E. Turner and Y.-Y. Pang contributed equally to this work.}

Current address of Q. Yan: Department of Plant Sciences and Plant Pathology, Montana State University, Bozeman, MT 59717.

${ }^{\dagger}$ Corresponding author: J. C. Anderson; anderje2@oregonstate.edu

Funding: We thank the Oregon State University Summer Undergraduate Research Experience (SURE) program for supporting this work through a fellowship awarded to S. E. Turner. We also thank the Department of Botany and Plant Pathology at Oregon State University for its generous support of the computing cluster. This work was funded by National Science Foundation Division of Integrative Organismal Systems award 1557694 to J. C. Anderson, United States Department of AgricultureNational Institute of Food and Agriculture (USDA-NIFA) award 2017-6701226126 to A. J. Weisberg, and USDA-NIFA award 2014-51181-22384 to J. H. Chang.

*The $\boldsymbol{e}$-Xtra logo stands for "electronic extra" and indicates that eight supplementary figures and one supplementary table are published online.

The author(s) declare no conflict of interest.

๑) 2020 The American Phytopathological Society expression independently of increased transcription of these genes. In addition to decreased response to defined sugar signals, a setA::Tn5 mutant had decreased T3SS deployment during infection and was compromised in its ability to grow in planta and cause disease. These data suggest that SetA is necessary for $P$. syringae to effectively respond to T3SS-inducing sugar signals encountered during infection.

Keywords: bacterial pathogenesis, DeoR-type regulator, metabolism, plant pathogens, Pseudomonas syringae, type III secretion, virulence regulation

Pseudomonas syringae are gram-negative bacteria that cause diseases on a wide variety of economically valuable crops, including tomato, bean, and tobacco (O'Brien et al. 2011). $P$. syringae can infect most aerial tissues of plants, yet are primarily studied based on their ability to cause disease on leaves (Getz et al. 1983; Hirano and Upper 2000). During the initial stages of infection, $P$. syringae move from the leaf surface into the apoplast, or interior space, through wounds or natural openings such as stomata (Xin and He 2013). Once in the apoplast, $P$. syringae can grow to high levels within a few days, ultimately causing visible disease symptoms that include necrotic lesions and chlorosis of leaf tissue (Abramovitch et al. 2006).

Like many host-adapted pathogens, $P$. syringae evades host defenses through the action of multiple specialized virulence mechanisms, including the type III secretion system (T3SS), a syringe-like apparatus that directly injects proteins termed effectors into host cells (Abramovitch et al. 2006; Grant et al. 2006). Once inside, type III effectors function primarily to suppress signaling pathways downstream of immune receptors, thereby allowing the bacteria to escape host defenses induced during infection (Cui et al. 2009). Consistent with their role in virulence, genes encoding T3SS structural proteins as well as effectors are not expressed in the absence of a host and must be induced at early stages of infection (Tang et al. 2006). A key regulator of type III secretion (T3S) by $P$. syringae is $\mathrm{HrpL}$, an ECF family alternative $\sigma$ factor that binds a consensus hrp box motif found within the promoters of T3SS-associated genes (Nissan et al. 2005; Tang et al. 2006; Xiao et al. 1994). Expression of $h r p L$ itself is induced by HrpR and HrpS, two NtrClike proteins that bind to the $h r p L$ promoter and recruit the $\sigma$ factor RpoN (б54) (Grimm and Panopoulos 1989; Hutcheson 
et al. 2001; Jovanovic et al. 2011; Rahme et al. 1991; Tang et al. 2006). HrpR and HrpS are encoded by a single hrpRS operon (Hutcheson et al. 2001) and function as a heterohexameric complex to regulate $h r p L$ expression (Jovanovic et al. 2011). Both HrpR and HrpS proteins lack receiver domains found in most NtrC family proteins, suggesting that promoter-binding activities of these proteins may not be directly regulated by cellular signals (Tang et al. 2006).

Early experiments to define the environmental conditions that induce T3SS deployment revealed that slightly acidic minimal media containing simple sugars and lacking complex nitrogen and carbon sources could induce the expression of T3SS-associated genes (Huynh et al. 1989; Rahme et al. 1992; Salmeron and Staskawicz 1993). Based on these results, it was hypothesized that these minimal media mimic the relatively nutrient-poor conditions encountered by $P$. syringae on the leaf surface and within the leaf apoplast during infection (Tang et al. 2006). Building from this, specific organic acids and amino acids exuded from plant tissues were identified as potent inducers of hrpL expression in P. syringae pv. tomato DC3000, a commonly used strain for investigating T3SS regulation (Anderson et al. 2014). These bioactive metabolites included primary metabolites such as citric acid and aspartic acid, as
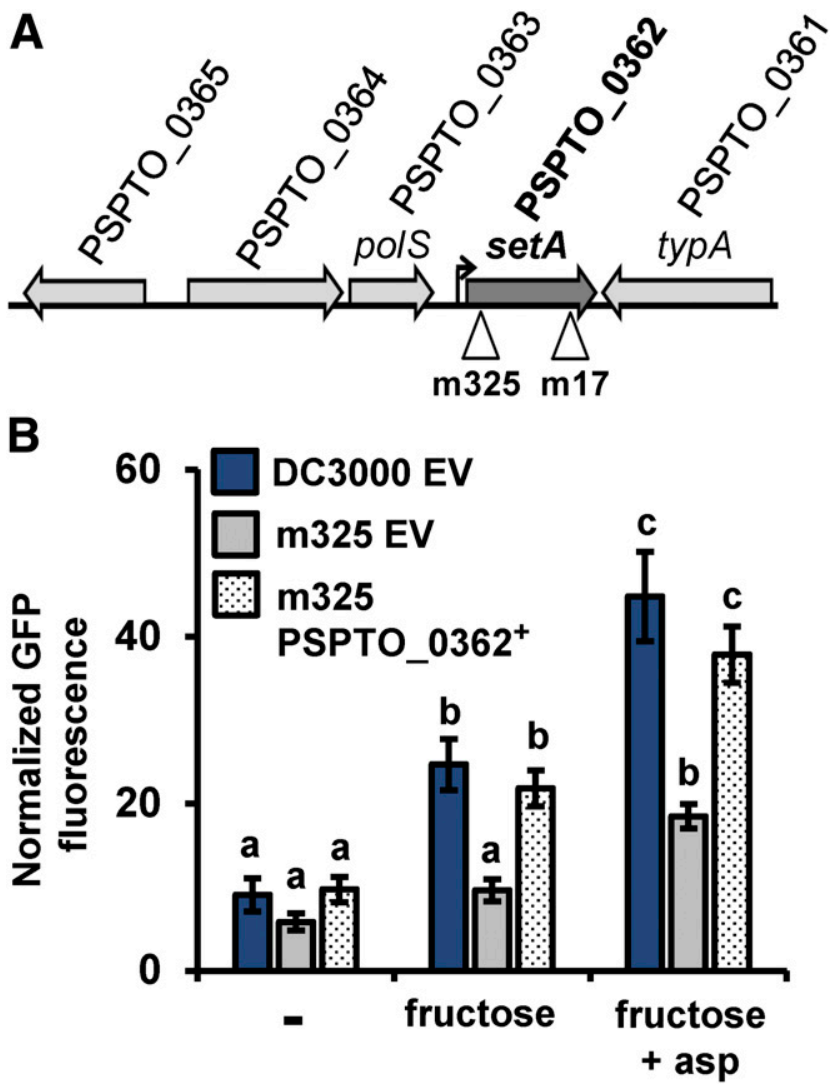

Fig. 1. Tn5 insertion in PSPTO_0362 decreases avrRpm1 expression in Pseudomonas syringae pv. tomato DC3000. A, Schematic of PSPTO_0362 locus in DC3000. Triangles show Tn5 insertions in mutant strains $\mathrm{m} 325$ and $\mathrm{m} 17$. B, Green fluorescent protein (GFP) fluorescence from DC3000, m325 (PSPTO_0362::Tn5), and a PSPTO_0362-complemented m325 strain (PSPTO_0362 ${ }^{+}$), each carrying an $a v r R p m 1_{\text {promoter: }}$ fp reporter plasmid. Bacteria were incubated in a minimal medium supplemented with or without $10 \mathrm{mM}$ fructose and $200 \mu \mathrm{M}$ aspartic acid (asp), as indicated. EV = empty complementation vector. Graphed are means \pm standard error of GFP fluorescence intensity from cultures $8 \mathrm{~h}$ posttreatment, $n=11$. Data were pooled from three independent experiments, $n=3$ to 4 per experiment. Lowercase letters denote significance groupings based on analysis of variance with pairwise $t$ tests and Tukey's honestly significant difference posthoc test, $P<0.05$. well as compounds such as hydroxybenzoic acid that are more closely associated with secondary metabolic pathways. Importantly, the bioactivity of these compounds required the presence of a simple sugar such as fructose or mannitol in the inducing medium, suggesting that multiple distinct classes of metabolites may coordinately regulate T3SS deployment by $P$. syringae. However, the genetic bases that link plant-derived metabolite signals to activation of the T3SS remain unresolved.

We report here that a gene encoding a previously uncharacterized deoxyribonucleoside regulator (DeoR)-type transcriptional regulator, sugar-induced expression of T3S A (SetA), is required for $P$. syringae DC3000 to maximally express its T3SS-encoding genes in response to sugars in culture media. We further show that setA is required for T3SS deployment and virulence of DC3000 during infection of Arabidopsis, suggesting that SetA plays an important role in regulating how $P$. syringae senses and responds to the host environment.

\section{RESULTS}

SetA is required for maximal fructose-induced expression of type III effector gene avrRpmI.

We screened a population of Tn5-mutagenized DC3000 for mutants that express decreased levels of the T3SS effectorencoding gene avrRpml in response to fructose and aspartic acid. The mutagenized strain carried a transcriptional reporter plasmid consisting of avrRpml fused to $g f p$ (Yan et al. 2019). We measured the amount of green fluorescent protein (GFP) fluorescence from individual Tn5-mutant colonies as a proxy for levels of avrRpml expression (see Materials and Methods for details of screen). From this screen, we isolated two independent mutant strains, $\mathrm{m} 17$ and $\mathrm{m} 325$, with Tn5 insertions in PSPTO_0362 (Fig. 1A), a gene predicted to encode a $28-k D$ DeoR-type transcriptional regulator with an N-terminal helix-turn-helix DNAbinding domain and a C-terminal metabolite-sensing domain. We used PCR-based genotyping and Sanger sequencing of the interrupted PSPTO_0362 locus in m17 and m325 to confirm the locations of the Tn 5 insertions (Supplementary Fig. S1; data not shown). The Tn5 insertions in $\mathrm{m} 17$ and $\mathrm{m} 325$ occurred at nucleotides +662 and +13 , respectively, relative to the predicted translation start site of PSPTO_0362.

To confirm decreased expression of T3SS-associated genes in $\mathrm{m} 17$ and $\mathrm{m} 325$, we cultured each mutant in a minimal medium supplemented with fructose (MMF) or with fructose and aspartic acid (MMFA), and measured avrRpml expression based on levels of GFP fluorescence from the $\operatorname{avrRpm} 1_{\text {promoter: }}$ $g f p$ reporter plasmid carried by each strain. Bacteria cultured in the same minimal medium (MM) without additional metabolites served as a negative control. Expression levels of avrRpm1 in both mutants were significantly lower relative to levels in DC3000 $8 \mathrm{~h}$ posttreatment with MMFA (Fig. 1B; Supplementary Fig. S2). We also detected a significant reduction in avrRpml expression in each mutant cultured in MMF (Fig. 1B; Supplementary Fig. S2). To confirm that decreased avrRpm1 expression was due to disruption of PSPTO_0362, we introduced into $\mathrm{m} 325$ and $\mathrm{m} 17$ a plasmid containing PSPTO_0362 under the control of a constitutive promoter. For both metabolite treatments, the plasmid carrying PSPTO_0362 restored avrRpm 1 expression in $\mathrm{m} 325$ and $\mathrm{m} 17$ to levels measured in DC3000 (Fig. 1B; Supplementary Fig. S2). We also measured the growth of DC3000 and m325 in King's B (KB) broth, and observed similar growth rates between these strains (Supplementary Fig. S3). Thus, loss of setA does not affect DC3000 fitness when grown in rich $\mathrm{KB}$ medium. Together, these data suggest that PSPTO_0362 is a positive regulator of fructoseinduced T3SS expression in DC3000. We named this gene setA. Because sugar is required for aspartic acid to induce 
T3SS genes (Anderson et al. 2014), we could not discern whether decreased avrRpm 1 expression in strains m325 and $\mathrm{m} 17$ is a phenotype specific to perception of aspartic acid, fructose, or possibly a combination of both metabolites. Therefore, we elected to primarily use only fructose and other sugars as inducing metabolites in all subsequent analyses.

SetA positively regulates $h r p L$ expression independently of altered $h r p R S$ or $\operatorname{rpoN}$ expression.

To place setA in the signaling cascade that regulates the T3SS of $P$. syringae, we next determined whether set $A$ is required for expression of $h r p L, h r p R S$, or $r p o N$. We fused the promoter sequences of these genes to $g f p$ within a broad host range plasmid, and introduced each of the reporter plasmids into DC3000, as well as m325 cured of the $a v r R p m 1_{\text {promoter: }}: f p$ reporter. We then cultured these reporter strains in $\mathrm{KB}$ broth and measured GFP fluorescence of each culture as a proxy for reporter gene expression. Expression of hrpRS and rpoN was detected in both DC3000 and m325 cultured in KB broth, and no significant difference in expression of these genes was measured between strains (Fig. 2A). In comparison, hrpL expression was much lower than hrpRS and rpoN expression in both DC3000 and m325 (Fig. 2A). Nevertheless, we detected a significant reduction in $h r p L$ expression in $\mathrm{m} 325$ compared with DC3000 under this treatment condition (Fig. 2A, inset). We then inoculated the same GFP reporter strains into MMF and measured GFP fluorescence of these cultures over a course of $12 \mathrm{~h}$. Expression of $h r p L$ was strongly induced in DC 3000 cultured in MMF (Fig. 2B). Expression of hrpL was also induced in $\mathrm{m} 325$ cultured in MMF yet was significantly lower compared with levels of $h r p L$ expression in DC3000 at all time points (Fig. 2B) (two-sample $t$ tests, $P<0.01$ ). In contrast to $h r p L$, GFP fluorescence from $h r p R S_{\text {promoter: }}: g f$ and $r p o N_{\text {promoter: }}: g f p$ strains initially declined prior to showing slight increases over the remainder of the time course (Fig. 2C and D). The initial decline was likely due to the turnover of GFP as cells acclimated to the MMF medium. No significant decrease in hrpRS or rpoN expression was observed between DC3000 and m325 at all time points (Fig. 2C and D) $(P>0.05$ for all comparisons based on $t$ tests). Based on these results, we conclude that set $A$ is required for maximal $h r p L$ expression in both $\mathrm{KB}$ and in MMF but is not required for $h r p R$ or $r p o N$ expression under the same treatment conditions.

setA is required for maximal avrRpml and $h r p L$ expression induced by multiple distinct sugars.

In addition to fructose, multiple simple sugars can induce T3SS gene expression, including the sugar alcohol mannitol, the disaccharide sucrose, and the monosaccharides galactose and glucose (Huynh et al. 1989). To assess whether setA is broadly required for sugar-induced expression of T3SS-encoding genes, we inoculated DC3000 and m325 avrRpm $1_{\text {promoter }}$ : $f p$ reporter strains into MM supplemented with either fructose, sucrose, glucose, galactose, or mannitol. All sugars significantly induced avrRpml expression in DC3000 over an 8-h time course, albeit with different kinetics (Fig. 3; Supplementary Fig. S4). Sucrose, galactose, and glucose induced higher levels of avrRpml expression relative to fructose and mannitol. These data suggest that sugar-specific differences may exist in cellular uptake, perception, or response pathways. Compared with DC3000, expression of avrRpml in m325 was significantly reduced in response to all sugars tested (Fig. 3; Supplementary Fig. S4). However, a significant increase in avrRpml expression was nonetheless detected in $\mathrm{m} 325$ in response to all sugars, indicating that setA-independent responses to sugar also contribute to increased expression of avrRpml (Supplementary Fig. S4). We also inoculated DC3000 and $\mathrm{m} 325 \mathrm{hrpL} L_{\text {promoter:gfp reporter }}$ strains into MM supplemented with the same panel of sugars, and measured a similar reduction in $h r p L$ expression in $\mathrm{m} 325$ in response to all sugars tested (Supplementary Fig. S5). We conclude from these data that $\operatorname{set} A$ is required for maximum expression of avrRpml and upstream regulator $h r p L$ in response to multiple inducing sugars. No decrease in growth of $\mathrm{m} 325$ relative to DC3000 was observed in any of the sugarsupplemented media (Supplementary Fig. S6). Thus, loss of SetA does not negatively impact the ability of DC3000 to use T3SS-inducing sugars as nutrients.

\section{Expression of setA is induced by T3SS-inducing} metabolites and is conditionally dependent on $h r p L$.

We next investigated the regulation of setA expression by making a $s e t A_{\text {promoter }}: g f p$ reporter plasmid and introduced this plasmid into DC3000 and $\mathrm{m} 325$. We first cultured these reporter strains in KB broth for $24 \mathrm{~h}$. Based on GFP fluorescence, setA was highly expressed in both DC3000 and the m325 mutant (Fig. 4A). No significant difference in setA expression between strains was measured. We also introduced the same $\operatorname{set}_{\text {promoter }}:$ ffp reporter plasmid into a DC3000 $\mathrm{hrpL}^{-}$strain (Zwiesler-Vollick et al. 2002). No significant difference in levels of GFP fluorescence was measured from this $h r p L^{-}$reporter strain compared with levels of fluorescence from DC3000 set $A_{\text {promoter }}: g f p$. These data indicate that neither HrpL nor SetA is required for setA expression in DC3000 cultured in rich medium (Fig. 4A).

We then inoculated the DC3000 set $A_{\text {promoter }}: g f p$ reporter strain into MMF or MMFA. MM lacking any inducing metabolites was also inoculated. Time course analysis of GFP fluorescence from these cultures revealed that expression of setA initially decreased from the high levels observed in $\mathrm{KB}$
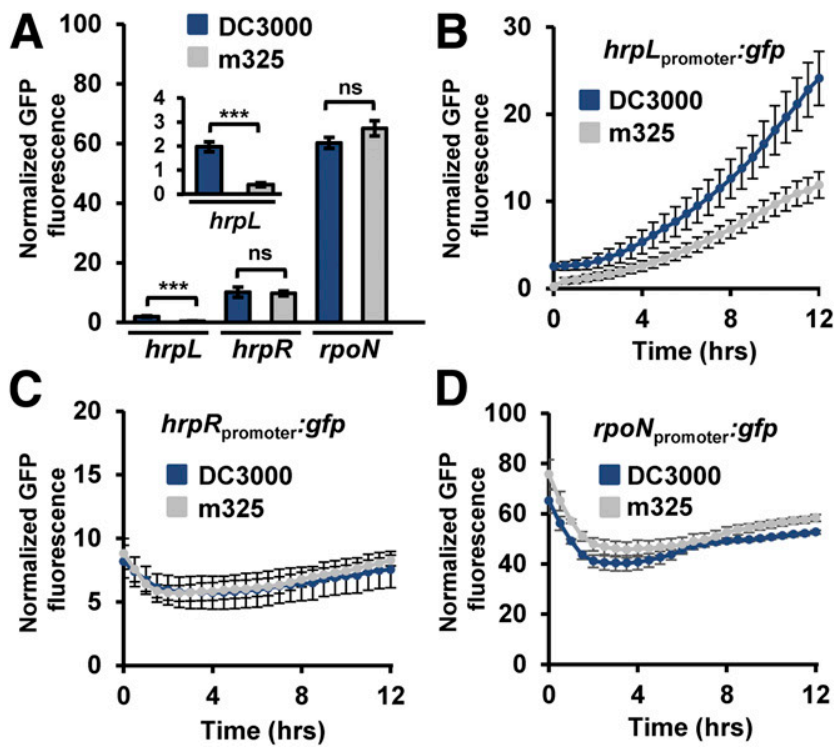

Fig. 2. Disruption of setA decreases $h r p L$ expression but does not alter $h r p R$ or rpoN expression in DC3000. A, Expression of $h r p L, h r p R$, and $r p o N$ in DC3000 and m325 (setA::Tn5) cultured in King's B medium for $24 \mathrm{~h}$. Graphed are means \pm standard error (SE) of green fluorescent protein (GFP) fluorescence from strains carrying $h r p L_{\text {promoter }}: g f p, h r p R_{\text {promoter: }} g f p$ or $r p o N_{\text {promoter }}: g f p$ reporter plasmids, $n=9$. Data were pooled from three experiments, $n=3$ per experiment. Inset shows the same $h r p L$ data graphed with a smaller Y-axis scale. Asterisks denote statistical significance based on pairwise $t$ test comparison, $P<0.001$. Abbreviation $\mathrm{ns}=$ not significant. $\mathbf{B}, \mathbf{C}$, and D, Bacteria from KB cultures (A) were washed and then inoculated directly into minimal medium containing $50 \mathrm{mM}$ fructose. Graphed are means \pm SE of GFP fluorescence from cultures at time points indicated, $n=13$. Data in each panel were pooled from three independent experiments, $n=3$ to 6 per experiment. 
broth (Fig. 4B). However, after approximately $4 \mathrm{~h}$, setA expression levels increased in DC3000 cultured in MMF compared with levels in bacteria cultured in the no-metabolite control medium (two-sample $t$ test at time $[\mathrm{T}]=8 \mathrm{~h}$ and all subsequent time points, $P<0.01$ ) (Fig. 4B). In comparison, setA was induced more rapidly and to higher levels in DC3000 treated with MMFA (two-sample $t$ test at $\mathrm{T}=6 \mathrm{~h}$ and all subsequent time points, $P<0.01$ ) (Fig. 4B). We conclude from these data that setA expression is responsive to both fructose and aspartic acid signals.

With the $h r p L^{-}$set $A_{\text {promoter }}: g f p$ reporter strain, we detected no significant difference in GFP fluorescence compared with DC3000 in response to fructose alone (two-sample $t$ test comparison of response by genotype at $\mathrm{T}=6 \mathrm{~h}$ and subsequent time points, $\alpha=0.05$ ) (Fig. 4C). However, in response to both fructose and aspartic acid, we detected a significant yet partial reduction in GFP fluorescence from this strain (two-sample $t$ test of responses by genotype at $\mathrm{T}=6 \mathrm{~h}, P<0.001$ ), indicating that $h r p L$ is required specifically for maximal aspartic acid-induced expression of setA (Fig. 4C). No reduction in GFP fluorescence was measured from the $\mathrm{m} 325 \operatorname{set} A_{\text {promoter }}: g f p$ strain in response to either metabolite treatment condition (Fig. 4D). Therefore, SetA is not required for its own expression under these conditions.

Genes encoding transcription factors are often located near their target promoters. Genes near setA include a predicted sorbitol dehydrogenase (pols, PSPTO_0363), a sorbitol/mannitol ABC transporter substrate-binding protein (PSPTO_0364), an AraC-type transcriptional regulator (PSPTO_0365), and typA (PSPTO_0361) encoding a ribosome-binding GTPase. PSPTO_ 0363 and PSPTO_0364 are in a predicted operon, whereas the other two genes are predicted to be monocistronic (Pseudomonas genome database) (Winsor et al. 2016) (Fig. 1A). To investigate whether these genes may be regulated by SetA, we individually cloned approximately $500 \mathrm{bp}$ of sequence upstream of each gene as a fusion with $g f p$, and tested expression of these GFP reporter constructs in DC3000 and m325. Based on GFP fluorescence, both PSPTO_0364 and polS reporter constructs were expressed in bacteria cultured in MMFA. However, no difference in the expression of these genes between DC3000 and m325 was detected (Supplementary Fig. S7). We did not detect abovebackground levels of GFP fluorescence from strains carrying typA:gfp, suggesting that this gene is not expressed under this treatment condition (Supplementary Fig. S7).

\section{SetA is required for DC3000 T3SS deployment and virulence during infection of Arabidopsis.}

To assess whether setA regulates the expression of T3SSencoding genes in planta, we syringe infiltrated DC3000 or m325, each carrying either an $h r p L_{\text {promoter }}: g f p$ plasmid or promoterless $g f p$ negative control plasmid, into leaves of Arabidopsis Col-0 plants. After $6 \mathrm{~h}$, we measured GFP fluorescence of leaf disks isolated from the infiltrated tissue. A significant increase in fluorescence was measured from tissue infiltrated with DC3000 hrp $L_{\text {promoter }}: g f p$ compared with tissue infiltrated with the DC3000 empty vector control strain, indicating that $h r p L$ expression during leaf infection can be detected with this GFP reporter (data not shown). In comparison with DC3000-infiltrated tissue, hrpL expression in $\mathrm{m} 325$ infiltrated tissue was significantly reduced (Fig. 5A). We measured bacteria levels in the same infected tissue at $6 \mathrm{~h}$ postinfection and observed no difference in the number of bacteria at this early time point (Supplementary Fig. S8).
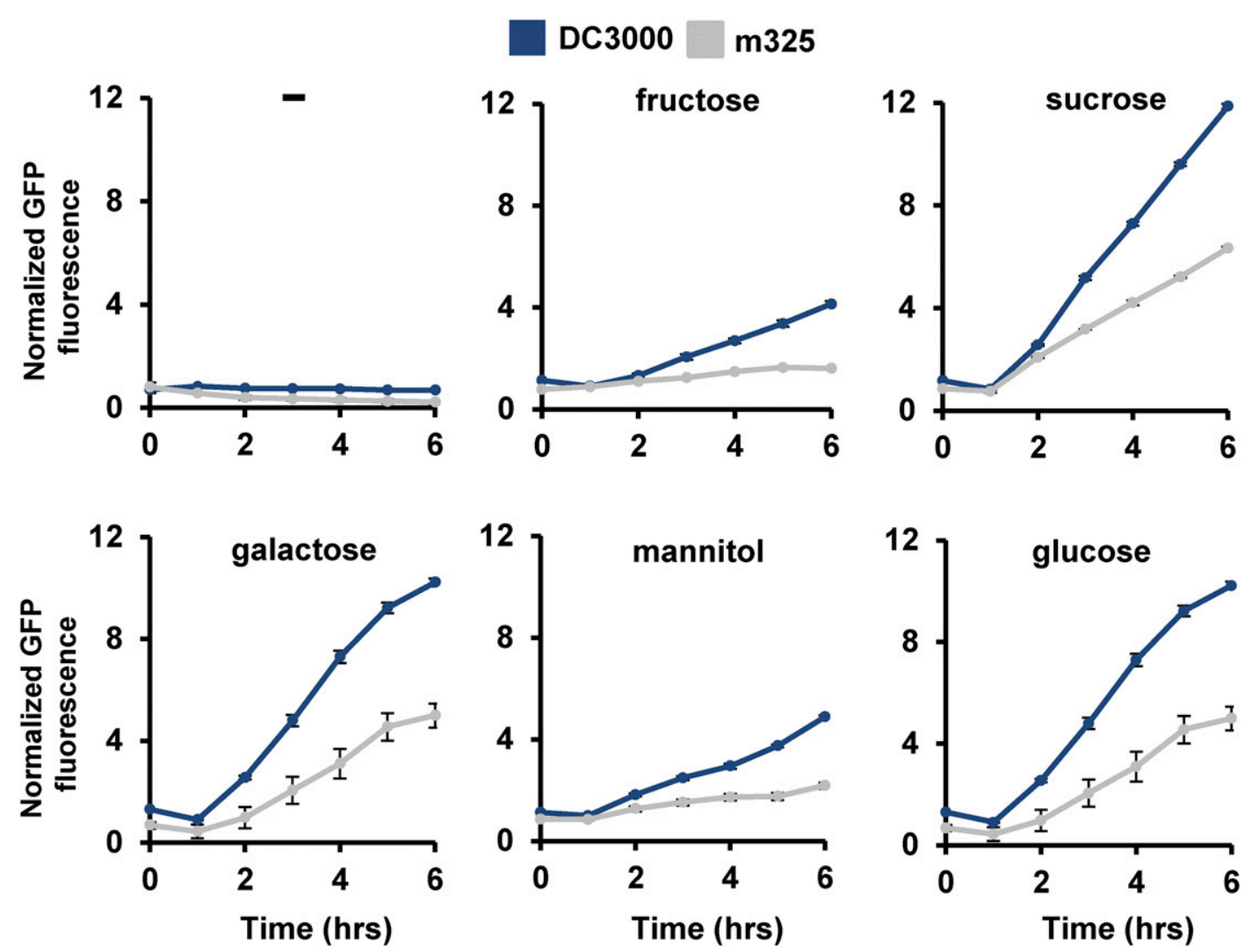

Fig. 3. DC3000 setA is required for maximum avrRpm1 expression induced by multiple distinct sugars. Time course analysis of avrRpm1 expression in DC3000 and m325 (setA::Tn5) cultured in minimal medium without sugar (-) or with $50 \mathrm{mM}$ fructose, $50 \mathrm{mM}$ sucrose, $50 \mathrm{mM}$ galactose, $50 \mathrm{mM}$ mannitol, or $50 \mathrm{mM}$ glucose, as indicated. Graphed in all panels are means \pm standard deviation of green fluorescent protein (GFP) fluorescence from strains carrying an avrRmm $1_{\text {promoter: }}:$ fp reporter, $n=4$. Data are representative of three independent experiments. 
Therefore, differences in $h r p L$ expression are not due to differences in bacterial populations. To confirm the observed decrease in T3SS gene expression, we used immunoblotting to detect levels of type III effector AvrPto in protein extracts prepared from infected leaf tissue. We observed reduced levels of AvrPto in m325-infiltrated tissue relative to DC3000infiltrated tissue $6 \mathrm{~h}$ postinfection (Fig. 5B), whereas no decrease in AvrPto abundance was observed in protein extracts from tissue infiltrated with $\mathrm{m} 325$ carrying a plasmid containing setA. These data show that setA positively regulates the expression of T3SS-associated genes during DC3000 infection of Arabidopsis leaves.

To investigate whether SetA is required for DC3000 virulence, we syringe infiltrated DC3000, m325, or m325 carrying a setA-expressing plasmid into Arabidopsis leaves. At 3 days postinfection, we observed a decrease in chlorotic disease symptoms on m325-infected leaves relative to DC3000 and the setA-complemented m325 strain (Fig. 6A). We used serial dilution plating of leaf tissue extracts to measure bacteria populations in infected leaves. Similar to disease symptoms, bacteria levels in $\mathrm{m} 325$-infected tissue were significantly reduced relative to DC3000-infected tissue at 3 days postinfection, and this decrease in bacteria levels was not observed with a setA-complemented m325 strain (Fig. 6B). Based on these data, we conclude that $\operatorname{set} A$ is required for full virulence of DC3000 during infection of Arabidopsis leaves.
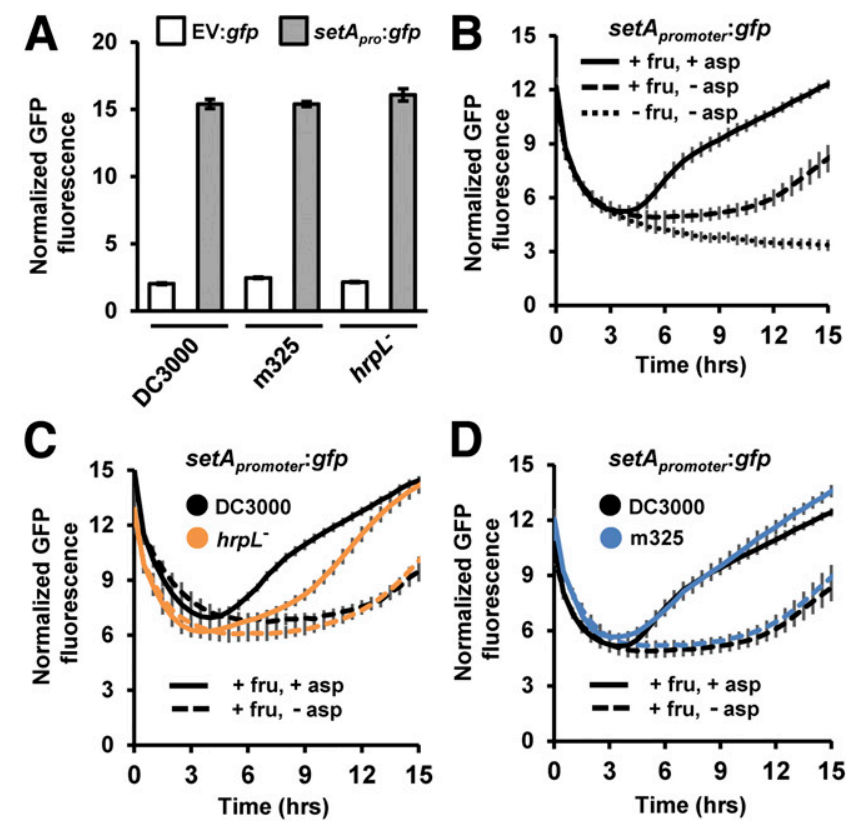

Fig. 4. Expression of $s e t A$ is induced by type III secretion-inducing metabolites and is conditionally dependent on hrpL. Measurements of green fluorescent protein (GFP) fluorescence from DC3000, m325, and $h r p L^{-}$ $s e t A_{\text {promoter }}: g f p$ reporter strains under different treatment conditions. A, GFP fluorescence from reporter strains cultured in King's B medium for $21 \mathrm{~h} . \mathrm{EV}=$ empty vector. Graphed are means \pm standard deviation, $n=3$. Data are representative of three independent experiments. B, Time course analyses of GFP fluorescence from DC3000 set $A_{\text {promoter }}: g f p$ reporter strain cultured in minimal medium supplemented with $200 \mu \mathrm{M}$ aspartic acid (asp) or $50 \mathrm{mM}$ fructose (fru), as indicated. Graphed are means \pm standard error (SE), $n=10$. $\mathbf{C}$ and $\mathbf{D}$, Time-course analyses of GFP fluorescence from DC3000 and m325 cultured in minimal medium supplemented with $200 \mu \mathrm{M}$ aspartic acid or $50 \mathrm{mM}$ fructose, as indicated. Graphed are means $\pm \mathrm{SE}, n=10$. Data in B to D were pooled from three independent experiments, $n=3$ to 4 per experiment. Data for DC3000 are the same in B and D.

\section{DISCUSSION}

In this work, we investigated the genetic basis of plant metabolite-induced expression of T3SS-associated genes in $P$. syringae DC3000. We discovered that setA is required for maximal sugar-induced expression of hrpL (Fig. 2; Supplementary Fig. S4), placing SetA genetically upstream of this master regulator. Although the molecular connection between SetA and $h r p L$ expression is unknown, our results show that SetA is not required for DC3000 to achieve wild-type levels of growth in media supplemented with sugars as the sole carbon source (Supplementary Fig. S6), or in rich KB medium (Supplementary Fig. S3), suggesting that the role of SetA in mediating expression of $h r p L$ is genetically separable from sugar catabolism processes necessary for growth. We further demonstrate that $s e t A$ is required for maximal $h r p L$ expression (Fig. 5A) and virulence (Fig. 6) during infection of Arabidopsis by DC3000. Therefore, SetA also functions in the response of DC3000 to virulence-inducing signals encountered within the host environment.

SetA is predicted to belong to the DeoR class of transcriptional regulators, a large family of proteins conserved in both gram-negative and gram-positive bacteria, as well as the
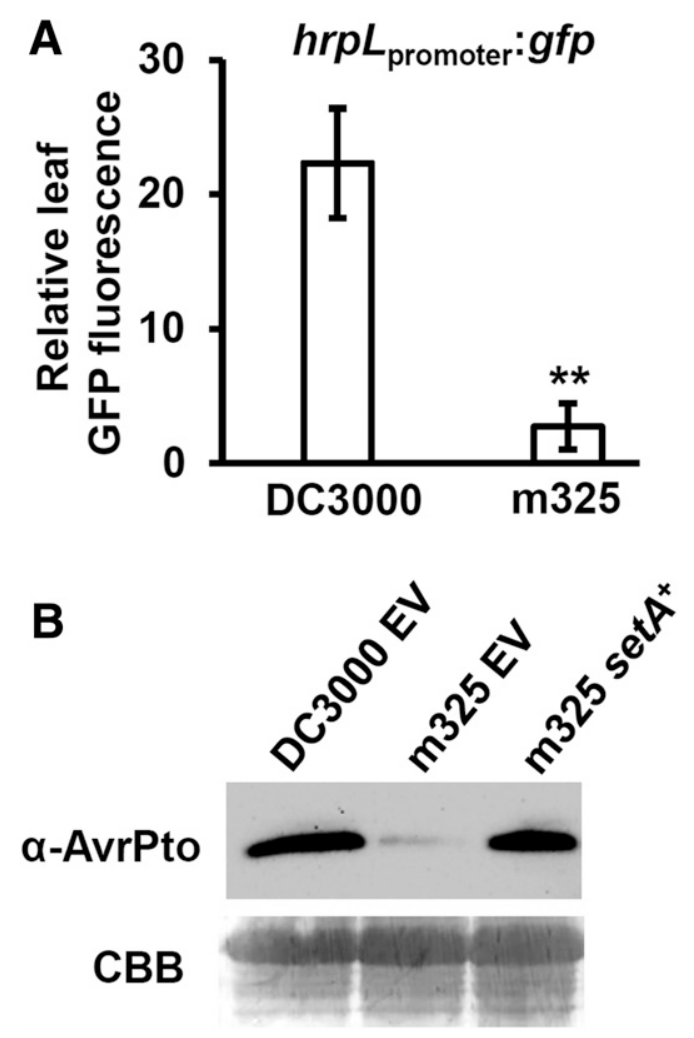

Fig. 5. Disruption of setA decreases expression of type III secretion systemassociated genes in DC3000 during infection of Arabidopsis leaves. A, Five-week-old Arabidopsis leaves were syringe infiltrated with $5 \times 10^{8}$ CFU/ml of DC3000 or m325 (setA::Tn5) carrying a $h r p L_{\text {promoter }}: g f p$ plasmid or empty vector $(E V)$ control plasmid. Graphed are means \pm standard error of green fluorescent protein (GFP) fluorescence from tissue infected with $h r p L_{\text {promoter }}: g f p$ reporter strains relative to fluorescence from tissue infected with strains carrying $\mathrm{EV}, n=12$. Asterisks denote statistical significance based on pairwise $t$ test comparison, $P<0.01$. B, Immunoblot analysis of AvrPto in Arabidopsis leaf tissue syringe infiltrated with $5 \times 10^{8}$ $\mathrm{CFU} / \mathrm{ml}$ of DC3000, m325 (setA::Tn5), or m325 carrying pME6010::setA $\left(\operatorname{set} \mathrm{A}^{+}\right) . \mathrm{EV}=$ empty vector pME6010. Tissue was collected $6 \mathrm{~h}$ postinfection. Upper panel is immunoblot detection with anti-AvrPto antibody and lower panel is Coomassie Brilliant Blue (CBB)-stained blot for loading control. Data in both panels are representative of three independent experiments. 
domain Archaea (Elgrably-Weiss et al. 2006; Martin et al. 2018). The founding member of this family is the DeoR protein of Escherichia coli. DeoR is a transcriptional repressor of deo genes that encode for enzymes required for catabolism of deoxyribonucleosides (Hammer and Dandanell 1989; Hammer-Jespersen and Munch-Peterson 1975). The N terminus of DeoR is a DNA-binding helix-turn-helix domain, whereas the $\mathrm{C}$ terminus is a sensor domain that binds deoxyribose5-phosphate, an intermediate of deoxyribonucleoside catabolism (Ge et al. 2016; Hammer and Dandanell 1989). In the presence of deoxyribonucleosides, deoxyribose-5-phosphate accumulates in the cell and binds to the $\mathrm{C}$ terminus of DeoR, resulting in structural changes that decrease DeoR binding to its operators, thereby allowing transcription of the deo operon to occur (Hammer-Jespersen 1983; Mortensen et al. 1989). Additional DeoR-like transcriptional regulators include LacR, GlpR, and IolR that regulate genes encoding catabolic enzymes for lactose, glycerol-phosphate, and inositol, respectively, in a diversity of bacteria (Freedberg and Lin 1973; Oskouian and Stewart 1990; Yoshida et al. 1997). In several cases, DeoR-type proteins have been shown to be necessary for virulence or environmental stress responses. In plant-pathogenic Agrobacterium tumefaciens, AccR regulates the expression of genes necessary to catabolize agrocinopines, sugar-phosphate conjugates produced in plant cells by enzymes encoded in the Agrobacterium T-DNA (Beck von Bodman et al. 1992; Subramoni et al. 2014). AccR constitutively binds to and represses the activity of target promoters in free-living bacteria. During
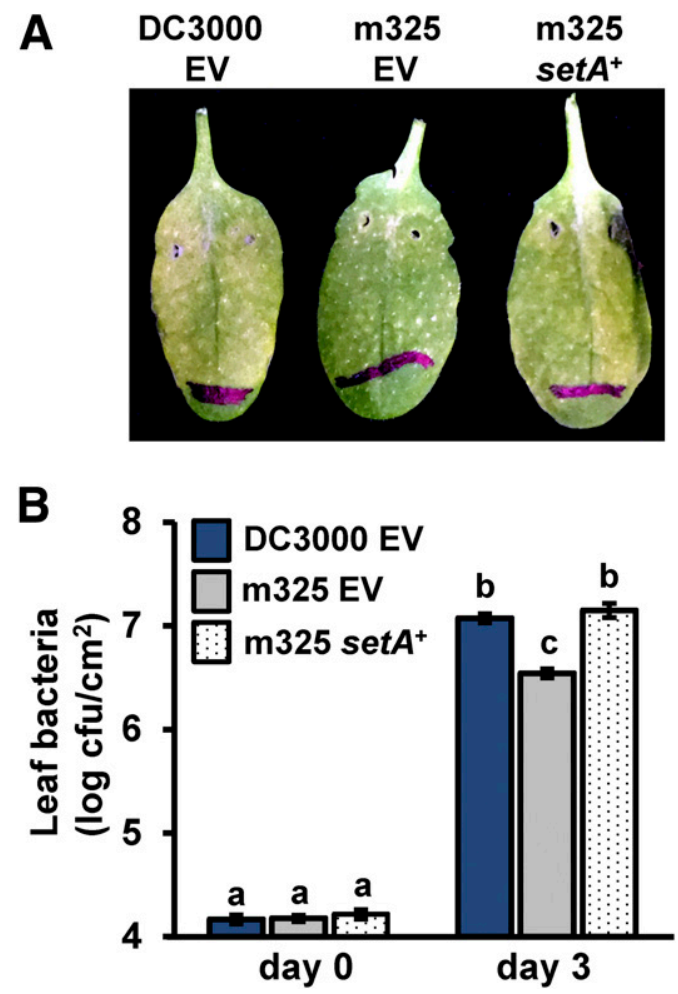

Fig. 6. DC3000 setA mutant is less virulent during infection of Arabidopsis. DC3000 and m325 carrying pME6010::setA plasmid (setA+) or empty pME6010 were syringe infiltrated into leaves of 5-week-old Arabidopsis plants. EV = empty vector. A, Photograph of disease symptoms on leaves 3 days postinfection. B, Leaf bacteria populations enumerated 0 and 3 days postinfection by serial dilution plating of leaf tissue extracts. Graphed are means \pm standard error of bacteria from four infected plants, $n=4$ for day 0 and $n=8$ for day 3 . Lowercase letters denote significance groupings based on pairwise $t$ tests, $P<0.001$. Results are representative of three independent experiments. infection, the accumulation of agrocinopines relieves the repressive activity of AccR, allowing for opine catabolic genes to be expressed (Subramoni et al. 2014). In the animal pathogen Brucella melitensis, loss of deoRl attenuates expression of virulence-promoting $\operatorname{vir} B$ operon, and in the opportunistic pathogen $P$. aeruginosa, loss of glmR, encoding a DeoR homolog, results in increased outer membrane permeability and hypersusceptibility to a broad range of antibiotics, mostly likely due to loss of GlmR repression of genes involved in peptidoglycan and LPS biosynthesis (Haine et al. 2005; Ramos-Aires et al. 2004).

Our data show that SetA is required for DC3000 to maximally express $h r p L$ in T3SS-inducing synthetic media and during infection of Arabidopsis leaf tissue. However, the mechanistic link between SetA and $h r p L$ is still not clear. A potential clue is that expression of $h r p R S$ and $r p o N$ was not altered in setA::Tn5 m325, suggesting that SetA regulates $h r p L$ independently of altered transcription of these upstream regulators. If SetA functions as a transcriptional repressor similar to many DeoR-type regulators, a parsimonious hypothesis is that SetA represses the transcription of a negative regulator of $h r p L$. The abundance of HrpR is negatively regulated by Lon protease-mediated degradation (Bretz et al. 2002), whereas HrpS activity is repressed by direct binding of an antiactivator protein HrpV (Preston et al. 1998; Wei et al. 2005). Therefore, SetA may be involved in regulating the production or activity of these proteins, or may negatively regulate the expression of a yet-unknown negative regulator of $h r p L$ expression. Alternatively, SetA may function as a transcriptional activator and regulate the expression of a gene encoding a yet-unknown positive regulator of $h r p L$, or directly regulate the $h r p L$ promoter itself. These hypotheses are not mutually exclusive, because decreased hrpL expression in m325 may reflect the combined activity of SetA acting as both an activator and repressor at multiple distinct promoters. Further experiments to identify potential target promoters and binding motifs of SetA will be necessary to further define the molecular function of SetA in regulating T3SS genes. It is important to note that the loss of setA did not completely eliminate sugar-induced expression of $h r p L$ (Supplementary Fig. S4). Therefore, additional SetA-independent pathways must exist that contribute to $h r p L$ induction in response to sugar signals.

Expression of setA itself was induced in response to fructose and aspartic acid, indicating that $s e t A$ is regulated by signaling pathways activated by these metabolites (Fig. 4B). Our genetic analyses show that setA expression in response to fructose is not dependent on HrpL or SetA (Fig. 4C and D). However, setA expression induced by fructose and aspartic acid was partially hrpL dependent (Fig. 4C). These data provide several insights into regulation of SetA and the nature of fructose- and aspartic acid-induced responses in DC3000. First, because setA expression remains at least partially intact in $\mathrm{hrpL}^{-}$and $\mathrm{setA}^{-}$ strains, one or more transcriptional regulators in DC3000 other than SetA and HrpL must regulate setA, both in response to fructose alone and in response to fructose and aspartic acid. We analyzed $500 \mathrm{bp}$ of DNA sequence upstream of setA using BPROM (Solovyev and Salamov 2011) and identified putative $\sigma^{70}$-dependent -10 and -35 elements upstream of the predicted translation start site (data not shown) but failed to identify any known transcription-factor binding sites. Second, because $h r p L$ is required for maximal setA expression in response to fructose and aspartic acid, and vice versa, this suggests that an interdependence exists between SetA and HrpL regulons under this specific treatment condition. We did not identify an hrp box necessary for HrpL binding (Tang et al. 2006) upstream of setA (data not shown). Therefore, the partial $h r p L$-dependent 
expression of setA in response to aspartic acid and fructose is likely indirect and may be mediated by the products of genes regulated by HrpL. Several genes encoding predicted transcription factors are regulated by HrpL (Lam et al. 2014), and these proteins are candidates for setA regulators. Finally, conditional dependence of setA expression on $h r p L$ in response to aspartic acid suggests that perception of aspartic acid does not simply amplify fructose-induced responses in DC3000 but, rather, elicits transcriptional outputs that are distinct from those induced by sugar alone. The perception and integration of distinct metabolic signals may be a way for $P$. syringae to finetune virulence responses based on host exometabolome profiles that may vary spatially or temporally during infection.

Multiple simple sugars as well as the sugar alcohol mannitol increased the growth of DC3000 in culture (Supplementary Fig. S6). Therefore, in addition to acting as signals to induce T3S, all of these metabolites can be internalized and catabolized by DC3000. An important issue related to SetA is the mechanism by which sugars induce expression of T3SS-associated genes. Signaling likely occurs through physical interaction between a sugar molecule (or a metabolite derived from sugar catabolism) and a corresponding protein that translates this interaction into a signaling output. Perception could occur extracellularly, possibly through cell surface receptors that detect sugars or sugar derivatives in the periplasm (Daddaoua et al. 2014). Alternatively, sugar perception could occur intracellularly. Fructose is imported by pseudomonads through a phosphoenolpyruvate transport system (PTS), whereas all other sugars are transported through dedicated non-PTS transport systems (Lessie and Phibbs 1984). Once inside the cell, simple mono- and disaccharides are converted into 6-phosphogluconate and are metabolized to pyruvate through the Entner-Doudoroff pathway, or enter the pentose phosphate pathway (Morris et al. 1995, Nikel et al. 2015). Because multiple distinct sugars induce T3SS deployment by DC3000, it is plausible that increased levels of a common catabolic pathway intermediate, or increased abundance or activity of an enzyme within these pathways, is a signal to induce T3S. In P. aeruginosa, the regulators PtxS and PtxR and two-component system GtrS/GltR control the expression of genes encoding sugar catabolism enzymes in response to specific glucose catabolites (Daddaoua et al. 2010, 2014; Udaondo et al. 2018). Both PtxR and GtrS/GltR also directly regulate the expression of the exotoxin A-encoding gene toxA, providing a direct link between sugar metabolism and virulence gene expression (Daddaoua et al. 2014; Hamood et al. 1995; Udaondo et al. 2018). Based on our data, we propose that SetA functions in a signaling pathway from intermediates of sugar catabolism to $h r p L$ expression. In support of this model, setA was not required for DC3000 growth on all sugar substrates tested (Supplementary Fig. S6), suggesting that SetA is involved in sensing the metabolic status of the cell rather than maintaining metabolic flux through catabolic pathways necessary for growth. Also, the presence of a predicted metabolite-binding domain on SetA suggests that its activity may be regulated directly by specific intracellular metabolites, possibly phosphorylated sugar intermediates. Experiments are underway to identify possible small-molecule ligands for the SetA sensor domain and to assess the functional requirements of both the sensor and DNA-binding domains for setA-dependent phenotypes.

\section{MATERIALS AND METHODS}

\section{Bacteria culture media.}

Strains of Pseudomonas syringae were cultured in a modified $\mathrm{KB}$ (King et al. 1954) broth (1\% [wt/vol] peptone, $1 \%$ tryptone, $0.1 \% \mathrm{MgSO}_{4} \cdot 7 \mathrm{H}_{2} \mathrm{O}, 0.1 \% \mathrm{~K}_{2} \mathrm{HPO}_{4}$, and $1 \%$ [vol/vol] glycerol), or on $\mathrm{KB}$ agar $(1.5 \%)$ plates. Strains of E. coli were cultured in lysogeny broth (LB) (Luria and Burrous 1957) or on LB agar $(1.5 \%)$ plates. For expression of T3SS-associated genes, $P$. syringae were cultured in a modified hrp-inducing $\mathrm{MM}$ (10 mM K $\mathrm{HPO}_{4} / \mathrm{KH}_{2} \mathrm{PO}_{4}[\mathrm{pH} 6.0], 7.5 \mathrm{mM}\left(\mathrm{NH}_{4}\right)_{2} \mathrm{SO}_{4}$, $3.3 \mathrm{mM} \mathrm{MgCl}_{2}$, and $1.7 \mathrm{mM} \mathrm{NaCl}$ ) (Anderson et al. 2014) supplemented with 10 to $50 \mathrm{mM}$ of fructose, galactose, glucose, sucrose, or mannitol alone or with $200 \mu \mathrm{M}$ aspartic acid. Sugars were prepared as 1-M stocks in water, and $0.2 \mu \mathrm{m}$ was filtered. and stored at room temperature. Aspartic acid was prepared as a 20 -mM stock in water, filtered through a $0.2-\mu \mathrm{m}$ membrane and stored at $-20^{\circ} \mathrm{C}$.

\section{Tn5 transposon mutagenesis and identification of $\operatorname{Tn} 5$ insertion sites.}

DC3000 carrying pBBR1-MCS2::avrRpm1:gfp (Chang et al. 2005; Rogan and Anderson 2019) was cultured overnight in $3 \mathrm{ml}$ of $\mathrm{KB}$ medium at $28^{\circ} \mathrm{C}$ with shaking. A $1.5-\mathrm{ml}$ aliquot of this culture was centrifuged at $16,000 \times g$ for $1 \mathrm{~min}$, and the resulting bacterial pellet was resuspended in $1 \mathrm{ml}$ of $\mathrm{KB}$ medium without antibiotics. The centrifugation and resuspension steps were repeated twice. E. coli carrying pUT::mini-Tn5 Sm/Sp (De Lorenzo et al. 1990) and E. coli carrying the helper plasmid pRK600 (Kessler et al. 1992) were cultured overnight at $37^{\circ} \mathrm{C}$ in $3 \mathrm{ml}$ of LB medium containing appropriate antibiotics. A $1.5-\mathrm{ml}$ aliquot of each $E$. coli culture was washed three times with LB lacking antibiotics. For each conjugation, a 100- $\mu$ l aliquot of washed DC3000 culture was combined with $10 \mu$ of each washed $E$. coli culture. The mixed culture was centrifuged at $16,000 \times g$ for $1 \mathrm{~min}$ to pellet the bacteria, resuspended in $30 \mu \mathrm{l}$ of $\mathrm{KB}$ medium, and spotted onto the surface of a sterile nitrocellulose membrane placed on $\mathrm{KB}$ agar. After $12 \mathrm{~h}$ at $28^{\circ} \mathrm{C}$, the bacteria were scraped from the nitrocellulose membrane, resuspended into $200 \mu \mathrm{l}$ of $\mathrm{KB}$ medium, and spread evenly onto the surface of a circular 100-mm-diameter nitrocellulose filter placed on the surface of a $\mathrm{KB}$ agar $(1.5 \%)$ plate containing spectinomycin $(150 \mu \mathrm{g} / \mathrm{ml})$, rifampicin $(50 \mu \mathrm{g} / \mathrm{ml})$, and kanamycin $(30 \mu \mathrm{g} / \mathrm{ml})$. The plate was incubated at room temperature for 3 days. To remove residual $\mathrm{KB}$ medium from the nitrocellulose, the filter was transferred to the surface of an agar plate consisting of $1.5 \%$ agar solidified in water. After $24 \mathrm{~h}$, the nitrocellulose membranes were transferred to the surface of a $1.5 \%$ agar plate containing $50 \mathrm{mM}$ fructose and $5 \mathrm{mM}$ aspartic acid and incubated at $23^{\circ} \mathrm{C}$. After $6 \mathrm{~h}$, GFP fluorescence of each colony was visually scored using a Leica MZFLIII stereomicroscope. Approximately 20,000 colonies were screened for decreased GFP fluorescence, and 400 were selected for further study. Colonies with reduced fluorescence were picked from the filter and grown overnight in $\mathrm{KB}$ media containing spectinomycin $(50 \mu \mathrm{g} / \mathrm{ml})$, rifampicin $(50 \mu \mathrm{g} / \mathrm{ml})$, and kanamycin $(30 \mu \mathrm{g} / \mathrm{ml})$ at $28^{\circ} \mathrm{C}$ in an incubated shaker. Glycerol was added to each overnight culture at a final concentration of $20 \%$ and the cultures were stored at $-80^{\circ} \mathrm{C}$.

Genomic DNA (gDNA) was isolated from $\mathrm{Tn} 5^{+}$mutants using the DNeasy Blood and Tissue DNA extraction kit (Qiagen). The isolated gDNA was quantified with the Qubit fluorometric DNA assay (Thermo Fisher Scientific), processed into sequencing libraries using the Nextera XT kit (Illumina), and sequenced using the Illumina Hiseq 3000 platform at The Center for Genomics and Research Biocomputing at Oregon State University. Bowtie2 with optional settings " - I O-X 1500 local-no-unal" (Langmead and Salzberg 2012) was used to map the resulting reads to the mini-Tn 5 transposon sequence (de Lorenzo et al. 1990). Soft clipped reads that mapped to mini-Tn5 (clipped CIGAR string containing ' $\mathrm{S}$ ') were then mapped to the DC3000 reference genome (NCBI assembly ID GCF_000007805.1) (Buell et al. 2003) using the Bowtie2 option "-local." to identify Tn5 insertion sites. To confirm Tn5 insertions in setA, oligonucleotides $0362 \mathrm{Up}$ and $\mathrm{Tn} 5 \mathrm{Sp} / \mathrm{Sm} \_R$ 
(Supplementary Table S1) that anneal upstream of PSPTO_0362 or 461 nucleotides from the $5^{\prime}$ end of $\mathrm{Tn} 5 \mathrm{Sp} / \mathrm{Sm}$ (de Lorenzo et al. 1990), respectively, were used in PCR to amplify Tn5: gDNA junctions of expected size from gDNA. A strain of $\mathrm{m} 325$ cured of the $a v r R p m 1_{\text {promoter }}$ : $f p$ plasmid was generated by serial culturing of $\mathrm{m} 325$ in $\mathrm{KB}$ broth followed by isolation of kanamycin-sensitive colonies on $\mathrm{KB}$ agar.

\section{Construction of GFP transcriptional reporter and $\operatorname{set} A$-complementation plasmids.}

Construction of transcriptional reporter plasmids pBBR1-MCS2:: avrRpm $1_{\text {promoter }}: g f p$ and pProbe-NT::hrpL $L_{\text {promoter: }}: g f p$ was described previously (Yan et al. 2019). To complement the setA::Tn5 mutation, the Gibson assembly method (Gibson et al. 2009) was used to construct a pME6010 vector carrying setA under the control of a constitutive kanamycin promoter. Sequences of oligonucleotides used for vector construction are provided in Supplementary Table S1. Briefly, oligonucleotides setA_F and setA_R were used to PCR amplify setA from DC3000 gDNA. In order to generate a linear vector for Gibson assembly, oligonucleotides pME6010_F1 and pME6010_R were used to amplify a 5,466-bp fragment from pME6010a, and pME6010_F2 and pME6010_R2 were used to amplify a 2,798-bp fragment of pME6010a. NEBuilder HiFi reaction mix (NEB) was used to assemble the resulting setA and pME6010 PCR products. The sequence of the setA insert in pME6010 was confirmed by Sanger sequencing. To construct transcriptional reporter plasmids, oligonucleotide pairs rpoNpro_F/rpoNpro_R, setApro_F/setApro_ R, 0361pro_F/0361pro_R, 0364pro_F/0364pro_R, and 0365pro_ F/0365pro_R were used to PCR amplify approximately $500 \mathrm{bp}$ of DNA upstream of their respective genes from the DC3000 genome. NEBuilder HiFi reaction mix (NEB) was used to subclone the resulting PCR products into $S m a I$-digested pPROBENT. Triparental mating was used to mobilize GFP reporter plasmids and the setA-complementation plasmid into $P$. syringae.

\section{Measurements of GFP fluorescence and growth of $P$. syringae cultured in synthetic media.}

$P$. syringae strains were streaked from $-80^{\circ} \mathrm{C}$ glycerol stocks onto $\mathrm{KB}$ agar plates containing appropriate antibiotics and grown for 2 to 3 days at room temperature prior to use. Bacteria were scraped from the surface of the plate, washed twice with sterile water, adjusted to an optical density at $600 \mathrm{~nm}\left(\mathrm{OD}_{600}\right)=$ 1.0 , and inoculated into wells of a 96-well microplate containing MM supplemented with 10 or $50 \mathrm{mM}$ fructose, glucose, galactose, mannitol, or sucrose, as indicated. The final bacteria density in each well was $\mathrm{OD}_{600}=0.1$, and total well volumes of 100 or $200 \mu \mathrm{l}$ were used. GFP fluorescence was measured using a Spark $10 \mathrm{M}$ plate reader (Tecan). For automated time-course experiments, the 96-well plate was shaken at $216 \mathrm{rpm}$ between measurements and a humidity cassette was used to prevent sample evaporation. GFP fluorescence of bacteria in each well was measured using excitation and emission wavelengths of 485 and $535 \mathrm{~nm}$, respectively. Growth of bacteria in 96-well plates was monitored by measuring the $\mathrm{OD}_{600}$ of cultures in each well (absorbance at $\lambda=600 \mathrm{~nm}$ ) using default settings, with a 1,000-ms settle time. GFP fluorescence values were normalized to $\mathrm{OD}_{600}$ and to background fluorescence from cultures of the same strain carrying a promoterless $g f p$ control plasmid. Data were normalized and averaged using the Tecan Magellan control software and Microsoft Excel. All normalized fluorescence values were divided by 10,000 to simplify graphing of data.

To measure gene expression in $P$. syringae cultured in $\mathrm{KB}$ broth, bacteria were grown for 1 day on $\mathrm{KB}$ agar, then inoculated into $3 \mathrm{ml}$ of $\mathrm{KB}$ broth. Cultures were incubated at $28^{\circ} \mathrm{C}$ with shaking for $21 \mathrm{~h}$. Plate reader measurements of GFP fluorescence were done as described above.
Measurements of $\boldsymbol{P}$. syringae growth in Arabidopsis leaves.

Arabidopsis Col-0 seed were surface sterilized, stratified, and plated onto Murashige-Skoog agar as described previously (Anderson et al. 2014). After 2 weeks, seedlings were transferred to Sunshine mix soil and maintained at $22^{\circ} \mathrm{C}$ in a 10 -hday growth chamber. For infection experiments, $P$. syringae were streaked onto $\mathrm{KB}$ agar from $-80^{\circ} \mathrm{C}$ glycerol stocks. After 2 to 3 days at room temperature, bacteria were scraped from the surface of the plate, resuspended in $1 \mathrm{ml}$ of water, and washed twice with $1 \mathrm{ml}$ of water, using a centrifuge to pellet bacteria between washes. After washing, the suspensions of bacteria were adjusted to an $\mathrm{OD}_{600}=0.001\left(1 \times 10^{6} \mathrm{CFU} / \mathrm{ml}\right)$ and syringe infiltrated into fully expanded leaves of 5-week-old Arabidopsis Col-0 plants. Infected plants were maintained in a $22^{\circ} \mathrm{C}$ growth room set to a 10 -h day length. Leaf bacterial populations were enumerated by spotting serial dilutions of leaf tissue extracts on $\mathrm{KB}$ agar plates as described previously (Anderson et al. 2014).

\section{Detection of $h r p L$ expression and AvrPto in $P$. syringae-infected Arabidopsis leaves.}

Fully expanded leaves of 5-week-old Arabidopsis plants were syringe infiltrated with inoculum at $5 \times 10^{8} \mathrm{CFU} / \mathrm{ml}$ $\left(\mathrm{OD}_{600}=0.5\right)$ of $\mathrm{DC} 3000$ or $\mathrm{m} 325$ prepared as described above. After $6 \mathrm{~h}$, a cork borer was used to remove $0.2-\mathrm{cm}^{2}$ leaf disks from the infected tissue. To detect AvrPto, five leaf disks were placed into a single $1.5-\mathrm{ml}$ microcentrifuge tube and frozen in liquid nitrogen. Total proteins were extracted from each sample using Trizol reagent (Ambion) and separated by sodium dodecyl sulfate-polyacrylamide gel electrophoresis. Immunoblotting using anti-AvrPto antibody was performed as previously described (Anderson et al. 2014). For detection of $h r p L$ expression, individual leaf disks that were inoculated with DC3000 and m325 containing $h r p L_{\text {promoter }}: g f p::$ PProbe-NT were floated on $200 \mu \mathrm{l}$ of water within wells of a black 96well plate (Greiner Bio-One) and a Tecan Spark 10M plate reader used to measure GFP fluorescence at excitation and emission wavelengths of 485 and $535 \mathrm{~nm}$, respectively, from each well.

\section{AUTHOR-RECOMMENDED INTERNET RESOURCE}

Pseudomonas genome database: www.pseudomonas.com

\section{LITERATURE CITED}

Abramovitch, R. B., Anderson, J. C., and Martin, G. B. 2006. Bacterial elicitation and evasion of plant innate immunity. Nat. Rev. Mol. Cell Biol. 7:601-611.

Anderson, J. C., Wan, Y., Kim, Y.-M., Pasa-Tolic, L., Metz, T. O., and Peck, S. C. 2014. Decreased abundance of type III secretion system-inducing signals in Arabidopsis mkpl enhances resistance against Pseudomonas syringae. Proc. Natl. Acad. Sci. U.S.A. 111:6846-6851.

Beck von Bodman, S., Hayman, G. T., Farrand S. K. 1992. Opine catabolism and conjugal transfer of the nopaline Ti plasmid pTiC58 are coordinately regulated by a single repressor. Proc. Natl. Acad. Sci. U.S.A. 89:643-647.

Bretz, J., Losada, L., Lisboa, K., and Hutcheson, S. W. 2002. Lon protease functions as a negative regulator of type III protein secretion in Pseudomonas syringae. Mol. Microbiol. 45:397-409.

Buell, C. R., Joardar, V., Lindeberg, M., Selengut, J., Paulsen, I. T., Gwinn, M. L., Dodson, R. J., Deboy, R. T., Durkin, A. S., Kolonay, J. F., Madupu, R., Daugherty, S., Brinkac, L., Beanan, M. J., Haft, D. H., Nelson, W. C., Davidsen, T., Zafar, N., Zhou, L., Liu, J., Yuan, Q., Khouri, H., Fedorova N., Tran, B., Russell, D., Berry, K., Utterback, T., Van Aken, S. E., Feldblyum, T. V., D’Ascenzo, M., Deng, W. L., Ramos, A. R., Alfano, J. R., Cartinhour, S., Chatterjee, A. K., Delaney, T. P., Lazarowitz, S. G., Martin, G. B., Schneider, D. J., Tang, X., Bender, C. L., White, O., Fraser, C. M., and Collmer, A. 2003. The complete genome sequence of the Arabidopsis and tomato pathogen Pseudomonas syringae pv. tomato DC3000. Proc. Natl. Acad. Sci. U.S.A. 100:10181-10186. 
Chang, J. H., Urbach, J. M., Law, T. F., Arnold, L. W., Hu, A., Gombar, S., Grant, S. R., Ausubel, F. M., and Dangl, J. L. 2005. A high-throughput, near-saturating screen for type III effector genes from Pseudomonas syringae. Proc. Natl. Acad. Sci. U.S.A. 102:2549-2554.

Cui, H., Xiang, T., and Zhou, J.-M. 2009. Plant immunity: A lesson from pathogenic bacterial effector proteins. Cell. Microbiol. 11:1453-1461.

Daddaoua, A., Krell, T., Alfonso, C., Morel, B., and Ramos, J. L. 2010. Compartmentalized glucose metabolism in Pseudomonas putida is controlled by the PtxS repressor. J. Bacteriol. 192:4357-4366.

Daddaoua, A., Molina-Santiago, C., de la Torre, J., Krell, T., and Ramos, J. L. 2014. GtrS and GltR form a two-component system: The central role of 2-ketogluconate in the expression of exotoxin A and glucose catabolic enzymes in Pseudomonas aeruginosa. Nucleic Acids Res. 42: 7654-7665.

de Lorenzo, V., Herrero, M., Jakubzik, U., and Timmis, K. N. 1990. MiniTn 5 transposon derivatives for insertion mutagenesis, promoter probing, and chromosomal insertion of cloned DNA in gram-negative eubacteria. J. Bacteriol. 172:6568-6572.

Elgrably-Weiss, M., Schlosser-Silverman, E., Rosenshine, I., and Altuvia, S. 2006. DeoT, a DeoR-type transcriptional regulator of multiple target genes. FEMS Microbiol. Lett. 254:141-148.

Freedberg, W. B., and Lin, E. C. 1973. Three kinds of controls affecting the expression of the glp regulon in Escherichia coli. J. Bacteriol. 115: 816-823.

Ge, B., Liu, Y., Liu, B., Zhao, W., and Zhang, K. 2016. Characterization of novel DeoR-family member from the Streptomyces ahygroscopicus strain CK-15 that acts as a repressor of morphological development. Appl. Microbiol. Biotechnol. 100:8819-8828.

Getz, S., Stephens, C. T., and Fulbright, D. W. 1983. Influence of developmental stage on susceptibility of tomato fruit to Pseudomonas syringae pv. tomato. Phytopathology 73:36-38.

Gibson, D. G., Young, L., Chuang, R. Y., Venter, J. C., Hutchison, C. A., 3rd, and Smith, H. O. 2009. Enzymatic assembly of DNA molecules up to several hundred kilobases. Nat. Methods 6:343-345.

Grant, S. R., Fisher, E. J., Chang, J. H., Mole, B. M., and Dangl, J. L. 2006. Subterfuge and manipulation: Type III effector proteins of phytopathogenic bacteria. Annu. Rev. Microbiol. 60:425-449.

Grimm, C., and Panopoulos, N. J. 1989. The predicted protein product of a pathogenicity locus from Pseudomonas syringae pv. phaseolicola is homologous to a highly conserved domain of several procaryotic regulatory proteins. J. Bacteriol. 171:5031-5038.

Haine, V., Sinon, A., Van Steen, F., Rousseau, S., Dozot, M., Lestrate, P., Lambert, C., Letesson, J. J., and De Bolle, X. 2005. Systematic targeted mutagenesis of Brucella melitensis $16 \mathrm{M}$ reveals a major role for GntR regulators in the control of virulence. Infect. Immun. 73: 5578-5586.

Hammer, K., and Dandanell, G. 1989. The deoR repressor from E. coli and its action in regulation-at-a-distance. Pages 79-91 in: Nucleic Acids and Molecular Biology. Nucleic Acids and Molecular Biology, Vol. 3. F. Eckstein and D. M. J. Lilley, eds. Springer, Berlin, Heidelberg, Germany.

Hammer-Jespersen, K. 1983. Nucleoside catabolism. Pages 203-258 in: Metabolism of Nucleotides. Nucleosides and Nucleobases in Microorganisms. A. Munch-Petersen, ed. Academic Press, London, U.K.

Hammer-Jespersen, K., and Munch-Petersen, A. 1975. Multiple regulation of nucleoside catabolizing enzymes: Regulation of the deo operon by the cyt $R$ and deoR gene products. Mol. Gen. Genet. 137:327-335.

Hamood, A. N., Colmer, J. A., Ochsner, U. A., and Vasil, M. L. 1995. Isolation and characterization of a Pseudomonas aeruginosa gene, ptxR, which positively regulates exotoxin A production. Mol. Microbiol. 21: 97-110.

Hirano, S. S., and Upper, C. D. 2000. Bacteria in the leaf ecosystem with emphasis on Pseudomonas syringae-a pathogen, ice nucleus, and epiphyte. Microbiol. Mol. Biol. Rev. 64:624-653.

Hutcheson, S. W., Bretz, J., Sussan, T., Jin, S., and Pak, K. 2001. Enhancerbinding proteins HrpR and HrpS interact to regulate hrp-encoded type III protein secretion in Pseudomonas syringae strains. J. Bacteriol. 183: 5589-5598.

Huynh, T. V., Dahlbeck, D., and Staskawicz, B. J. 1989. Bacterial blight of soybean: Regulation of a pathogen gene determining host cultivar specificity. Science 245:1374-1377.

Jovanovic, M., James, E. H., Burrows, P. C., Rego, F. G., Buck, M., and Schumacher, J. 2011. Regulation of the co-evolved HrpR and HrpS AAA+ proteins required for Pseudomonas syringae pathogenicity. Nat. Commun. 2:177.

Kessler, B., de Lorenzo, V., and Timmis, K. N. 1992. A general system to integrate lacZ fusions into the chromosomes of gram-negative eubacteria: Regulation of the Pm promoter of the TOL plasmid studied with all controlling elements in monocopy. Mol. Gen. Genet. 233: 293-301.

King, E. O., Ward, M. K., and Raney, D. E. 1954. Two simple media for the demonstration of pyocyanin and fluorescin. J. Lab. Clin. Med. 44: 301-307.

Lam, H. N., Chakravarthy, S., Wei, H. L., BuiNguyen, H., Stodghill, P. V., Collmer, A., Swingle, B. M., and Cartinhour, S. W. 2014. Global analysis of the HrpL regulon in the plant pathogen Pseudomonas syringae pv. tomato DC3000 reveals new regulon members with diverse functions. PLoS One 9:e106115.

Langmead, B., and Salzberg, S. L. 2012. Fast gapped-read alignment with Bowtie 2. Nat. Methods 9:357-359.

Lessie, T. G., and Phibbs, P. V., Jr. 1984. Alternative pathways of carbohydrate utilization in pseudomonads. Annu. Rev. Microbiol. 38: 359-388.

Luria, S. E., and Burrous, J. W. 1957. Hybridization between Escherichia coli and Shigella. J. Bacteriol. 74:461-476.

Martin, J. H., Sherwood Rawls, K., Chan, J. C., Hwang, S., Martinez-Pastor, M., McMillan, L. J., Prunetti, L., Schmid, A. K., and Maupin-Furlow, J. A. 2018. GlpR is a direct transcriptional repressor of fructose metabolic genes in Haloferax volcanii. J. Bacteriol. 200:e00244-19.

Morris, V. L., Jackson, D. P., Grattan, M., Ainsworth, T., and Cuppels, D. A. 1995. Isolation and sequence analysis of the Pseudomonas syringae pv. tomato gene encoding a 2,3-diphosphoglycerate-independent phosphoglyceromutase. J. Bacteriol. 177:1727-1733.

Mortensen, L., Dandanell, G., and Hammer, K. 1989. Purification and characterization of the deoR repressor of Escherichia coli. EMBO J. 8: 325-331.

Nikel, P. I., Chavarría, M., Fuhrer, T., Sauer, U., and de Lorenzo, V. 2015. Pseudomonas putida KT2440 strain metabolizes glucose through a cycle formed by enzymes of the Entner-Doudoroff, Embden-MeyerhofParnas, and pentose phosphate pathways. J. Biol. Chem. 290: 25920-25932.

Nissan, G., Manulis, S., Weinthal, D. M., Sessa, G., and Barash, I. 2005. Analysis of promoters recognized by $\mathrm{HrpL}$, an alternative sigma-factor protein from Pantoea agglomerans pv. gypsophilae. Mol. Plant-Microbe Interact. 18:634-643.

O'Brien, H. E., Desveaux, D., and Guttman, D. S. 2011. Next-generation genomics of Pseudomonas syringae. Curr. Opin. Microbiol. 14:24-30.

Oskouian, B., and Stewart, G. C. 1990. Repression and catabolite repression of the lactose operon of Staphylococcus aureus. J. Bacteriol. 172: 3804-3812.

Preston, G., Deng, W. L., Huang, H. C., and Collmer, A. 1998. Negative regulation of hrp genes in Pseudomonas syringae by HrpV. J. Bacteriol. 180:4532-4537.

Rahme, L. G., Mindrinos, M. N., and Panopoulos, N. J. 1991. Genetic and transcriptional organization of the hrp cluster of Pseudomonas syringae pv. phaseolicola. J. Bacteriol. 173:575-586.

Rahme, L. G., Mindrinos, M. N., and Panopoulos, N. J. 1992. Plant and environmental sensory signals control the expression of hrp genes in Pseudomonas syringae pv. phaseolicola. J. Bacteriol. 174:3499-3507.

Ramos-Aires, J., Plésiat, P., Kocjancic-Curty, L., and Köhler, T. 2004 Selection of an antibiotic-hypersusceptible mutant of Pseudomonas aeruginosa: Identification of the GlmR transcriptional regulator. Antimicrob. Agents Chemother. 48:843-851.

Rogan, C. J., and Anderson, J. C. 2019. Isolation and characterization of plant metabolite signals that induce type III secretion by the plant pathogen Pseudomonas syringae. Methods Mol. Biol. 1991:115-126.

Salmeron, J. M., and Staskawicz, B. J. 1993. Molecular characterization and hrp dependence of the avirulence gene avrPto from Pseudomonas syringae pv. tomato. Mol. Gen. Genet. 239:6-16.

Solovyev, V., and Salamov, A. 2011. Automatic annotation of microbial genomes and metagenomic sequences. Pages 61-78 in: Metagenomics and its Applications in Agriculture, Biomedicine and Environmental Studies. R. W. Li, ed. Nova Science Publishers

Subramoni, S., Nathoo, N., Klimov, E., and Yuan, Z. C. 2014. Agrobacterium tumefaciens responses to plant-derived signaling molecules. Front. Plant Sci. 5:322.

Tang, X., Xiao, Y., and Zhou, J. M. 2006. Regulation of the type III secretion system in phytopathogenic bacteria. Mol. Plant-Microbe Interact. 19:1159-1166.

Udaondo, Z., Ramos, J. L., Segura, A., Krell, T., and Daddaoua, A. 2018. Regulation of carbohydrate degradation pathways in Pseudomonas involves a versatile set of transcriptional regulators. Microb. Biotechnol. 11:442-454.

Wei, C. F., Deng, W. L., and Huang, H. C. 2005. A chaperone-like HrpG protein acts as a suppressor of $\mathrm{HrpV}$ in regulation of the Pseudomonas syringae pv. syringae type III secretion system. Mol. Microbiol. 57:520-536. 
Winsor, G. L., Griffiths, E. J., Lo, R., Dhillon, B. K., Shay, J. A., and Brinkman, F. S. 2016. Enhanced annotations and features for comparing thousands of Pseudomonas genomes in the Pseudomonas genome database. Nucleic Acids Res. 44:D646-D653.

Xiao, Y., Heu, S., Yi, J., Lu, Y., and Hutcheson, S. W. 1994. Identification of a putative alternate sigma factor and characterization of a multicomponent regulatory cascade controlling the expression of Pseudomonas syringae pv. syringae Pss61 hrp and hrmA genes. J. Bacteriol. 176: $1025-1036$.

Xin, X. F., and He, S. Y. 2013. Pseudomonas syringae pv. tomato DC3000: A model pathogen for probing disease susceptibility and hormone signaling in plants. Annu. Rev. Phytopathol. 51:473-498.
Yan, Q., Rogan, C. J., and Anderson, J. C. 2019. Development of a Pseudomonas syringae-Arabidopsis suspension cell infection system for investigating host metabolite-dependent regulation of type III secretion and pattern-triggered immunity. Mol. Plant-Microbe Interact. 32:527-539.

Yoshida, K. I., Aoyama, D., Ishio, I., Shibayama, T., and Fujita, Y. 1997. Organization and transcription of the myo-inositol operon, iol, of Bacillus subtilis. J. Bacteriol. 179:4591-4598.

Zwiesler-Vollick, J., Plovanich-Jones, A. E., Nomura, K., Bandyopadhyay, S. Joardar, V., Kunkel, B. N., and He, S. Y. 2002. Identification of novel hrp-regulated genes through functional genomic analysis of the Pseudomonas syringae pv. tomato DC3000 genome. Mol. Microbiol. 45: 1207-1218. 